\title{
Advanced Torque and Current Control Techniques for PMSMs with a Real-time Simulator Installed Behavior Motor Model
}

\author{
Ryo Tanabe* Student Member, Kan Akatsu* Member
}

(Manuscript received May 18, 2015, revised Oct. 2, 2015)

\begin{abstract}
This paper presents advanced torque and current control techniques for Permanent Magnet Synchronous Motors (PMSMs) with a real-time simulator which has a nonlinear motor model. This model is called "Behavior motor model", and it is developed based on finite element analysis results considering non-linear characteristics that include spatial harmonics and magnetic saturation. The real-time simulator is implemented within a circuit simulator that couples the behavior motor model with switching circuits in real-time, and it can be applied to torque and current control as an advanced controller. In this paper, the torque and current control of a PMSM with the proposed system is presented. Effectiveness of this technique is verified by performing simulations and experiments.
\end{abstract}

Keywords: Behavior motor model, PMSMs drive system, real time simulator

\section{Introduction}

Permanent Magnet Synchronous Motors (PMSMs) have been widely used in various industrial applications due to their high efficiency and high power density characteristics.

In general, PMSMs drive systems are developed based on simplified mathematical model. In this model, the distributions of the inductance and linkage flux density due to rotor magnets are assumed as sinusoidal. Consequently, the $d q$ transformation method gives simple voltage and torque equation expressed with constant motor parameters. Because of this modeling, PMSMs drive system can be easily constructed by controller design techniques for DC machines. However, PMSMs typically have nonlinear characteristics such as the spatial harmonics and magnetic saturation $^{(1)(2)}$. The nonlinear characteristics degrade the performance of torque and current control based on simplified mathematical model because this drive system is controlled as a linear system.

In PMSMs which have the nonlinear characteristics, the pulsating torque is caused by interaction between excitation current and spatial harmonics in the linkage flux. Torque ripples may degrade speed and position control and cause large acoustic noises and vibrations. In previous researches, the optimal current command for the torque smoothness are achieved by developing torque controllers with mathematical model which has spatially dependent machine parameters has been proposed ${ }^{(3)-(5)}$. However, this technique requires amount of off line data for look up tables. If the magnetic saturation is also taken into account the machine parameters depend on not only the position but also current amplitude. This may cause the model construction to be complicated.

Furthermore, the realization of the optimal excitation current to achieve torque smoothness requires high performance

\footnotetext{
* Shibaura Institute of Technology (M \& E Energy Conversion Lab.)

3-7-5, Toyosu, Koto-ku, Tokyo 135-8548, Japan
}

current controller. The current feed-forward control gives optimal voltage commands to achieve desired current based on inverse PMSMs model. The current feed-forward controller has already been developed in the linear system ${ }^{(6)-(8)}$. However, in the case of nonlinear machine, the inverse model cannot give optimal voltage commands because of the nonlinearity of the machine. Precise voltage equation model can be obtained by considering the nonlinear characteristics ${ }^{(9)}$. However, as previously noted, the model construction is much complicated.

This paper presents advanced torque and current control techniques by using a real time simulator (high speed calculator) which has a precise PMSMs model. Precise PMSMs model is created by Finite Element Analysis (FEA) which can take into account the spatial harmonics and magnetic saturation. In the previous research, this model is called as a "behavior motor model" and this model is applied to a circuit simulator such as MATLAB/Simulink. In this paper, the coupling analysis between the behavior motor model and the circuit simulator is installed in the real time simulator as a controller of PMSM drive system. Therefore, the controller enables to achieve the advanced control method by using the instantaneous analysis results. In this paper, torque ripple control and high performance current control based on a feed forward control of PMSM by using the proposed technique is presented. Effectiveness of this technique is verified by performing some experiments.

\section{Conventional PMSM Control System}

In this section, the linear model of PMSM is firstly introduced. In general, the control system is developed by simplified mathematical model which is presented linear characteristics of PMSM in $d q$ synchronized rotor reference frame. The torque equation is described as follow:

$$
T_{e}=P_{n}\left\{\Psi_{d}+\left(L_{d}-L_{q}\right) i_{d}\right\} i_{q}
$$

where $T_{e}, P_{n}, \Psi_{d}, L_{d}, L_{q}, i_{d}$ and $i_{q}$, are torque, the number 


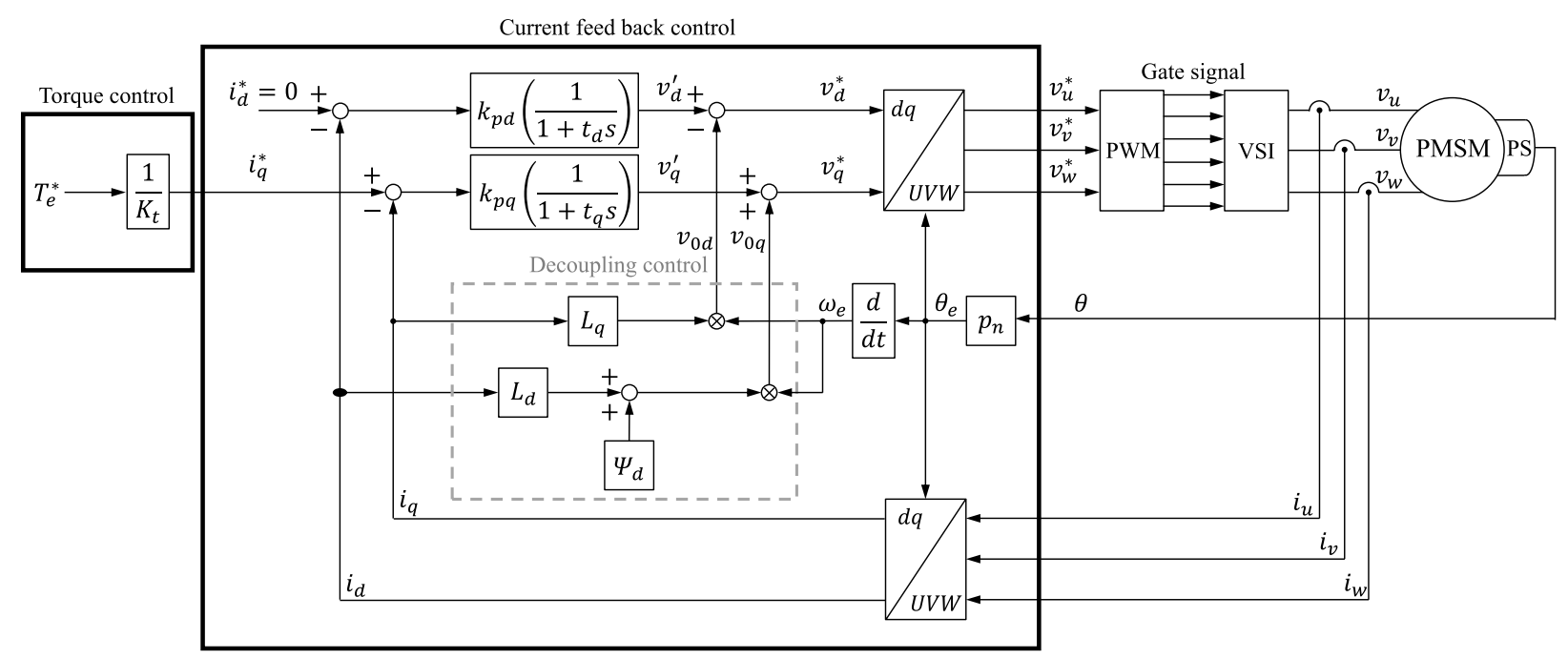

Fig. 1. Conventional PMSM control system

of pole pairs, $d$-axis linkage flux due to the rotor magnets, $d$-axis inductance, $q$-axis inductance, $d$-axis armature current and $q$-axis armature current, respectively. In case the $d$-axis current is a constant value, the torque has a linear characteristic with $q$-axis current.

The voltage differential equation is described as follow:

$$
\left[\begin{array}{l}
v_{d} \\
v_{q}
\end{array}\right]=R\left[\begin{array}{l}
i_{d} \\
i_{q}
\end{array}\right]+\left[\begin{array}{cc}
L_{d} & 0 \\
0 & L_{q}
\end{array}\right] \frac{d}{d t}\left[\begin{array}{l}
i_{d} \\
i_{q}
\end{array}\right]+\omega_{e}\left(\left[\begin{array}{cc}
0 & -L_{q} \\
L_{d} & 0
\end{array}\right]\left[\begin{array}{l}
i_{d} \\
i_{q}
\end{array}\right]+\left[\begin{array}{c}
0 \\
\Psi_{d}
\end{array}\right]\right)
$$

where $R$ and $\omega_{e}$ are the armature resistance, and angular electrical velocity, respectively. The current dynamics is described by differential equation based on (2) as follow:

$$
\frac{d}{d t}\left[\begin{array}{c}
i_{d} \\
i_{q}
\end{array}\right]=\left[\begin{array}{cc}
-\frac{R}{L_{d}} & \frac{\omega_{e} L_{q}}{L_{d}} \\
-\frac{\omega_{e} L_{d}}{L_{q}} & -\frac{R}{L_{q}}
\end{array}\right]\left[\begin{array}{c}
i_{d} \\
i_{q}
\end{array}\right]+\left[\begin{array}{cc}
\frac{1}{L_{d}} & 0 \\
0 & \frac{1}{L_{q}}
\end{array}\right]\left[\begin{array}{c}
v_{d} \\
v_{q}
\end{array}\right]-\left[\begin{array}{c}
0 \\
\frac{\omega_{e} \Psi_{d}}{L_{q}}
\end{array}\right]
$$

Figure 1 shows the block diagram of PMSMs control system which has torque and current controller based on (1) and (3).

2.1 Conventional Torque Control The torque control generates current command due to torque constant under an assumption that the relationship between torque and current is a linear characteristic (if $d$-axis current is zero). Therefore, the current command is generated as constant value according to torque command. However, in this control, the pulsating torque is caused because the relationship between current and torque is not linear by spatial harmonics of PMSM.

2.2 Conventional Current Control The current control works to achieve the current command. In general, the PI controller and decoupling controller are designed based on (2) is used as current controller. However, this controller may exhibit bandwidth limit and is not suited to cover the full critical range of harmonics frequencies. Therefore, the desired current is not completely excited. Adding that, this control cannot achieve a fast response because of its bandwidth limitation.

\section{Proposed Nonlinear Control System}

In this section, a proposed nonlinear control system based on FEA is described. The proposed control system is developed based on a behavior motor model which presents nonlinear characteristics of PMSMs. The behavior motor model has 3-D table data of inductance, magnet flux and torque as the function based on current amplitude, current phase and rotor position ${ }^{(10)}$.

In general, the construction of 3D-table data requires some complex processes such as the data interpolation. However, in this research, acquisition, interpolation, and construction of the machine parameter data are automatically implemented by computer software with the FEA (JMAG-RT produced by JSOL Corporation is used in this research). In addition, the behavior motor model is easily applied to the circuit simulator such as MATLAB/Simulink. This coupling method is implemented as a controller of PMSM drive system by using a real time simulator. This controller can take into account nonlinearities of not only tested machines but also external drive circuits.

In the proposed method, the sampling period is required as fast as possible because the FEA motor model uses rotor position signal to consider spatial harmonics. The accuracy of rotor position signal brings effectiveness of the spatial harmonics information. The sampling time should be decided depend on the data amount of the coupling circuit.

3.1 Drive System Setup Figure 2 shows the experimental set up. Drive system developed by MAT$\mathrm{LAB} /$ Simulink with the behavior motor model is installed in the real time simulator (LT-RTSimII produced by DSP Technology Co. Ltd is used in this research). The real time simulator communicates with fast A/D converter to take the analog signal of actual system into the real time simulator. The real time simulator outputs the PWM pulses to the voltage source inverter. The tested motor is rotated at a constant speed by a servo motor system. In addition, the behavior motor models and tested motor are synchronized each other by detecting the rotor position.

3.2 Verification of the Behavior Motor Model Figure 3 shows tested motor models. Specifications of the tested 


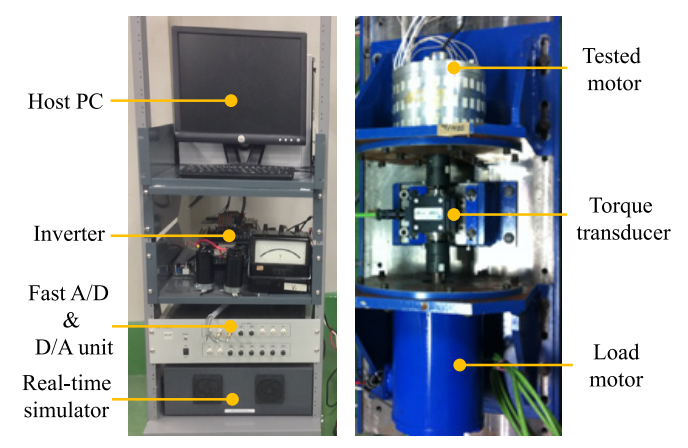

Fig. 2. Drive system setup

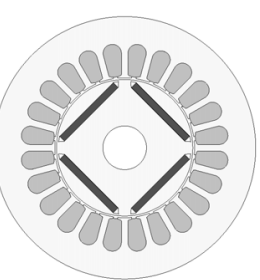

(a) Model A

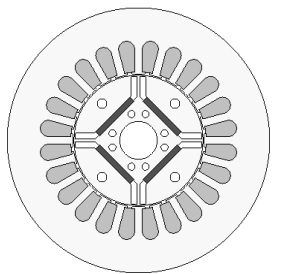

(b) Model B
Fig. 3. Test motor models

Table 1. Specification of test motor model

\begin{tabular}{|c|c|c|}
\hline & Model A & Model B \\
\hline Rated voltage [V] & 100 & 165 \\
\hline Rated current [Arms] & 7 & 3 \\
\hline Rated speed [rpm] & 1200 & 1800 \\
\hline Magnetic linkage flux $\Psi_{d}[\mathrm{mWb}]$ & 250.0 & 158.0 \\
\hline$d$-axis inductance $L_{d}[\mathrm{mH}]$ & 5.0 & 10.7 \\
\hline$q$-axis inductance $L_{q}[\mathrm{mH}]$ & 10.0 & 26.3 \\
\hline Winding resistance $R[\mathrm{ohm}]$ & 0.46 & 0.814 \\
\hline Number of pore pairs & 2 & 2 \\
\hline
\end{tabular}

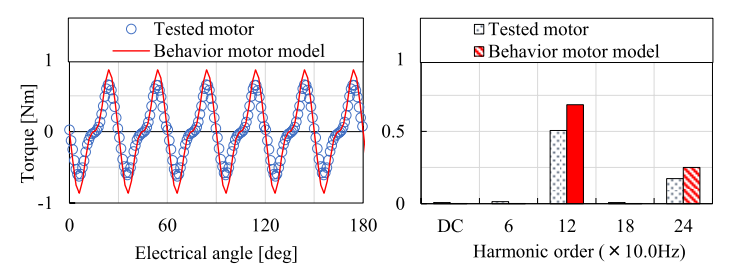

(a) Cogging torque waveforms and FFT results

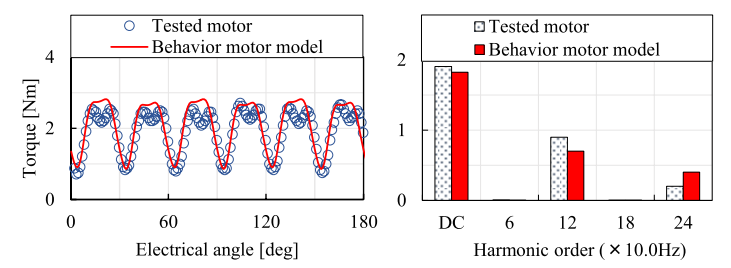

(b) Load torque waveforms and FFT results ( $d$-axis current is $0 \mathrm{~A}, q$-axis current is $4 \mathrm{~A}$, and rotation speed is $300 \mathrm{~min}^{-1}$ )

Fig. 4. Characteristics comparison of Model A

motors are shown in Table 1. Model A and Model B are used for torque ripple control and current control tests.

Figure 4 shows the characteristics comparison between the behavior motor model and tested motor of model A. As shown in Fig. 4(a), the cogging torque waveform and FFT results calculated by the behavior motor model corresponds with the tested motor output. As shown in Fig. 4(b), the behavior motor model can simulates $24^{\text {th }}$ and $48^{\text {th }}$ harmonics component which are main component of torque ripples.

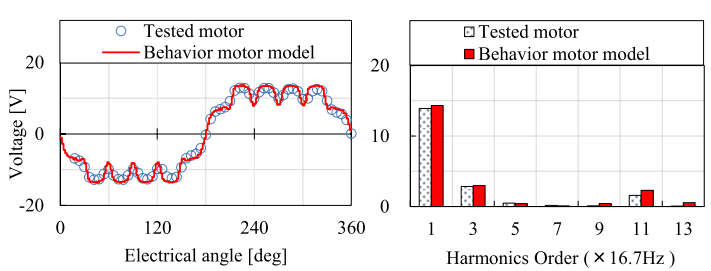

(a) U phase back EMF waveforms and FFT results (Rotation speed is $500 \mathrm{~min}^{-1}$ )
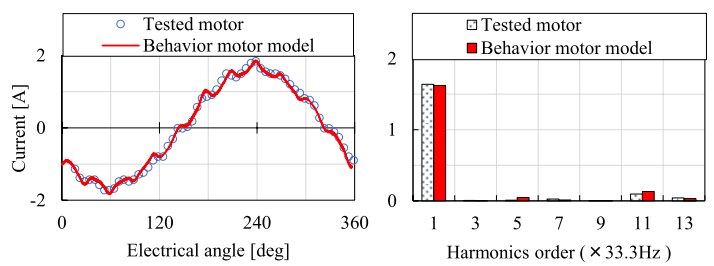

(b) U phase current waveforms and FFT results (Current is $2 \mathrm{~A}$, Current phase is 30 degree and rotation speed is $1000 \mathrm{~min}^{-1}$ )

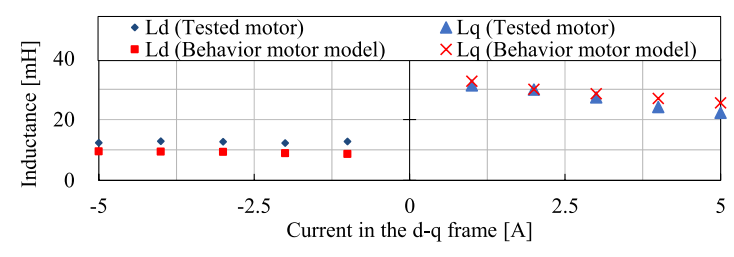

(c) $d, q$-axis inductance

Fig. 5. Characteristics comparison of Model B

From these results, the behavior motor model can calculate precise output torque includes ripples. Therefore, this model gives accurate estimated instantaneous torque.

Figure 5 shows the characteristics comparison between the behavior motor model and tested motor of model B. As shown in Fig. 5(a), the U-phase back EMF waveform and FFT results calculated by the behavior motor model corresponds with output of tested motor. In Fig. 5(b), the U-phase current waveform calculated by the behavior motor model is almost identical with excitation current of the tested motor. In Fig. 5(c), $q$-axis inductance which is calculated by behavior motor model corresponds with inductance which is measured from tested motor includes magnetic saturation characteristics. From these results, the behavior motor model can calculate precise instantaneous motor behavior including nonlinear characteristics. Therefore, this model enables to design the inverse model and to estimation of the instantaneous current of the tested motor in the current control.

\section{Proposed Torque Control}

In this section, a proposed torque control is described. Figure 6 shows the system of the proposed torque ripple control. In the proposed torque ripple control, the instantaneous torque is estimated by the behavior motor model from the simulated excitation current. This estimated torque includes characteristics of torque ripple. The current command generated by the torque controller is the optimal current to achieve torque smoothness. Therefore, the torque ripple is reduced compared with the conventional one. In addition, the excitation current which is applied the behavior motor model is estimated in the real time simulator. Hence, the gain of torque PI controller can be high because noises which are generated by sensors are not included in the system. In the simulation, the voltage signal is output by ideal voltage source. 


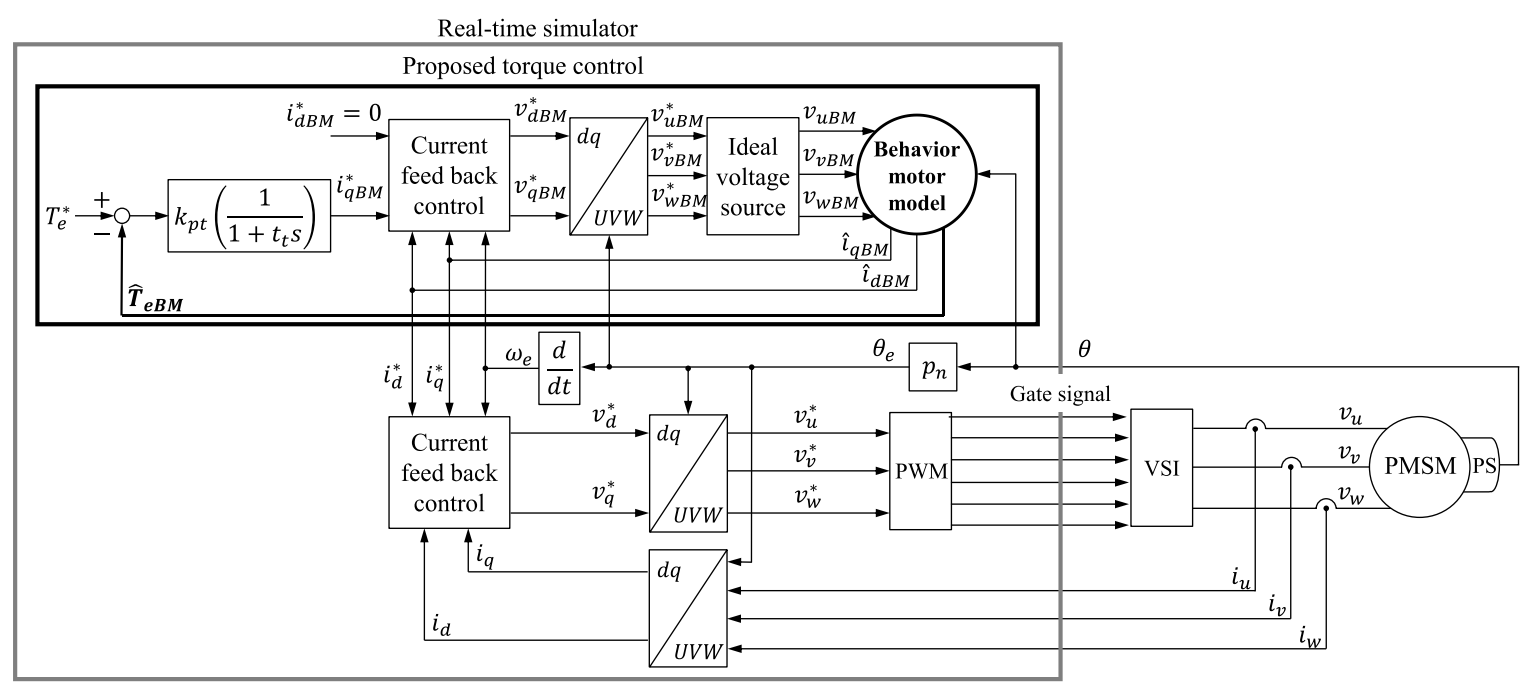

Fig. 6. Proposed torque control system
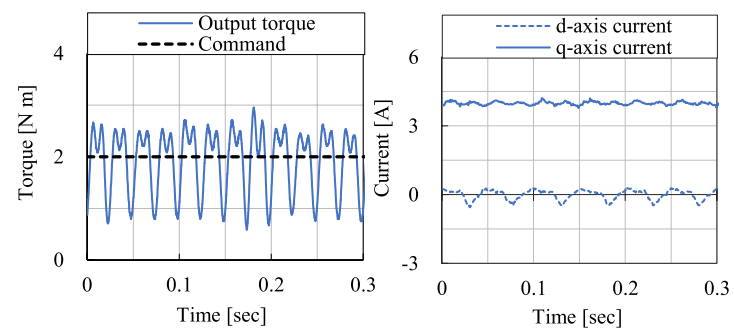

(a) Conventional method (Without torque ripple control)
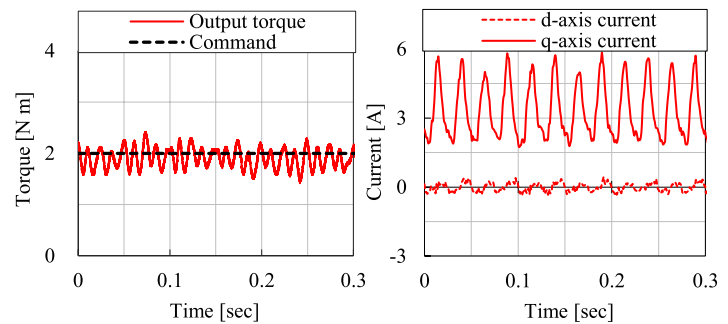

(b) Proposed method (With torque ripple control)
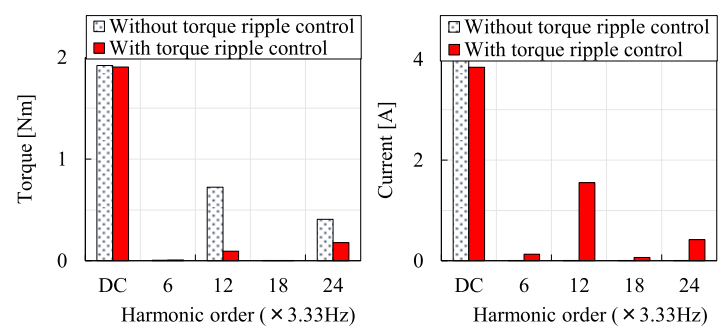

(c) FFT results

Fig. 7. Experimental results of torque ripple control (Output torque is shown in left side and $q$-axis current is shown in right side)

In fact, the output voltage is generated by voltage source inverter. Therefore, the output includes $6^{\text {th }}$ harmonics due to dead time and voltage drops witch is not considered in simulation. However, the $6^{\text {th }}$ harmonics of the torque ripple due to the inverter is much smaller than the torque ripple due to spatial harmonics. Thus, the $6^{\text {th }}$ harmonics generated by inverter is negligible in this paper. In the proposed method, optimal current command is just calculated in the simulation. Then, current control works to achieve excited current of the
Table 2. Experimental condition of torque control

\begin{tabular}{|c|c|}
\hline Torque command $[\mathrm{N} \mathrm{m}]$ & 2.0 \\
\hline Rotation speed $[\mathrm{rpm}]$ & 100 \\
\hline Current phase [degree] & 0 \\
\hline DC link voltage $[\mathrm{V}]$ & 100 \\
\hline Carrier frequency $[\mathrm{kHz}]$ & 10 \\
\hline Simulator sampling time $[\mu \mathrm{sec}]$ & 50 \\
\hline
\end{tabular}

actual motor with current reference. It means the effects of the voltage drops of the device can be ignored.

Figure 7 shows the experimental results of the conventional torque control and the proposed torque ripple control. The condition of this verification is shown in Table 2 and motor model A is used for the experimental test. As shown in Figs. 7(a) and (b), it is confirmed that the torque ripple is compensated by the proposed torque ripple control. Especially in Fig. 7(c), the $24^{\text {th }}$ and $48^{\text {th }}$ harmonics components are greatly reduced. As shown in Fig. 7(b), the pulsating current as the optimal current to achieve torque smoothness is confirmed.

Therefore, using the estimated instantaneous torque by the behavior motor model enables to reduce the torque ripple. From these results, the proposed torque ripple control which uses the real time simulator installed behavior motor model is verified to be reducing the torque ripple of PMSM.

Even in the case of using reluctance torque, the $d$-axis current reference should be given, the $q$-axis current reference is calculated by the PI regulator as optimal current reference to reduce torque ripple include the reluctance torque.

\section{Proposed Current Control}

In this section, a proposed current control is described. Figure 8(a) shows the control system of the proposed current control which is consisted of the inverse model design part, voltage limit compensation part and PI feed-back control part. Figure 8(b) shows a block diagram of the voltage limit compensation part. The inverse model design part works for generating optimal voltage command to achieve desired current using precise motor parameters obtained from FEA. In this research, this system is called as an "inverse 


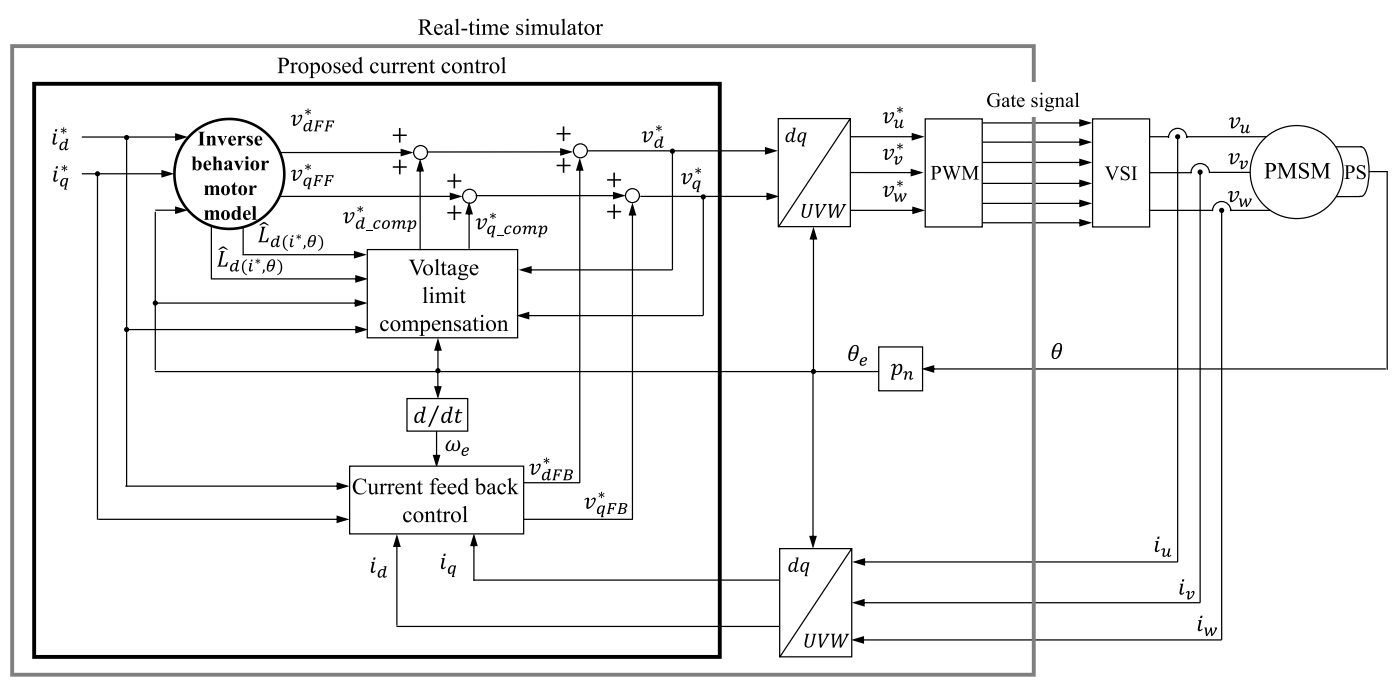

(a) Perspective of proposed current control system

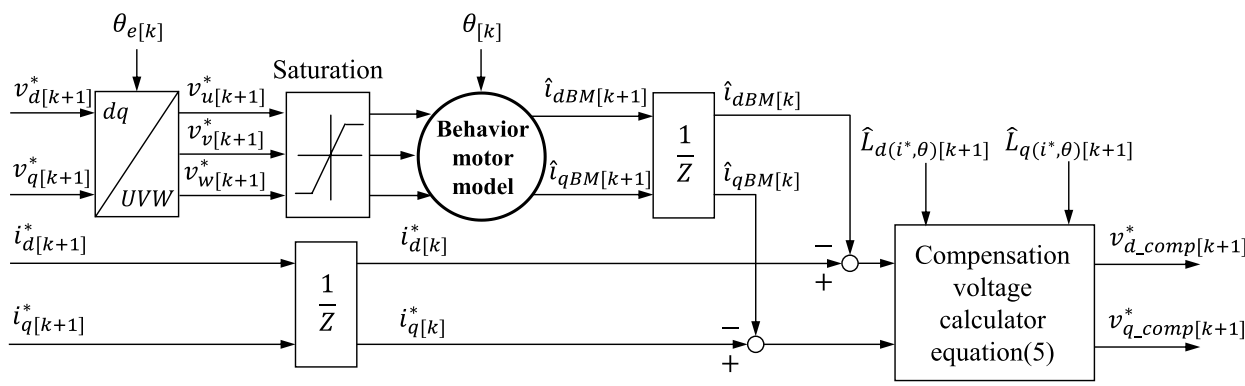

(b) Voltage limit compensation part

Fig. 8. Proposed current control system

behavior motor model". The feed forward voltage command is calculated using precise motor parameters obtained from FEA and (2) as follow:

$$
\begin{aligned}
{\left[\begin{array}{c}
v_{d F F}^{*} \\
v_{q F F}^{*}
\end{array}\right]=} & R\left[\begin{array}{c}
i_{d}^{*} \\
i_{q}^{*}
\end{array}\right]+\left[\begin{array}{cc}
\hat{L}_{d\left(i^{*}, \theta\right)} & 0 \\
0 & \hat{L}_{q\left(i^{*}, \theta\right)}^{*}
\end{array}\right] \frac{d}{d t}\left[\begin{array}{l}
i_{d}^{*} \\
i_{q}^{*}
\end{array}\right] \\
& +\omega_{e}\left(\left[\begin{array}{cc}
0 & -\hat{L}_{q\left(i^{*}, \theta\right)} \\
\hat{L}_{d\left(i^{*}, \theta\right)} & 0
\end{array}\right]\left[\begin{array}{l}
i_{d}^{*} \\
i_{q}^{*}
\end{array}\right]+\left[\begin{array}{c}
0 \\
\hat{\Psi}_{d\left(i^{*}, \theta\right)}
\end{array}\right]\right)
\end{aligned}
$$

where $v_{d}^{*}, v_{q}^{*}, i_{d}^{*}, i_{q}^{*}, L_{d\left(i^{*}, \theta\right)}, L_{q\left(i^{*}, \theta\right)}$ and $\hat{\Psi}_{d\left(i^{*}, \theta\right)}$ are the $d$-axis voltage command, $q$-axis voltage command, $d$-axis current command, $q$-axis current command, $d$-axis inductance according to $d$-axis, $q$-axis current and rotor position, $q$-axis inductance according to $d$-axis, $q$-axis current and rotor position, and $d$-axis linkage flux due to rotor magnets according $d$-axis, $q$-axis current and rotor position, respectively. Those parameters have influence of magnetic saturation and spatial harmonics because of dependence of current and rotor position. Therefore, this part can generate optimal voltage command without modeling errors.

However, the inverse behavior motor model cannot consider the voltage limitation due to DC link voltage. Because of the voltage limitation, the ideal current response in transient state is not achieved and the controller does not correctly work. The inverse behavior model calculates optimal voltage command under the assumption that instantaneous current before sampling accordance with current reference. In the case of the voltage saturation, this assumption is not achieved. To be correct operation, the compensation part makes accordance instantaneous current with current reference.

In the proposed controller, the compensation voltage command is generated from the error of between current reference and estimation instantaneous current in the voltage limit compensation part. The compensation voltage command is written in discrete system as follow:

$$
\left[\begin{array}{c}
v_{d \_c o m p}^{*}[k+1] \\
v_{q_{-} \operatorname{comp}[k+1]}^{*}
\end{array}\right]=\left[\begin{array}{cc}
\hat{L}_{d\left(i^{*}, \theta\right)[k+1]} & 0 \\
0 & \hat{L}_{q\left(i^{*}, \theta\right)[k+1]}
\end{array}\right] \frac{1}{T_{s}}\left[\begin{array}{l}
i_{d[k]}^{*}-\hat{i}_{d M B[k]} \\
i_{q[k]}^{*}-\hat{i}_{q M B[k]}
\end{array}\right]
$$

where $v_{d_{-} \text {comp }}^{*}, v_{q_{-} \text {comp }}^{*}, T_{s}$, and $k$ are $d$-axis compensation voltage command, $q$-axis compensation voltage command, sampling time, and number of sampling, respectively. If DC link voltage is enough, this compensation part does not work.

In general, using the differential operation is usually difficult to calculate because of noises of sensors. However, in the proposed current controller, the differential operation of the current is estimated by the behavior motor model, the actual current detected by the current sensor is not used for this algorithm. Therefore, the voltage limit compensation part does not effect to the stability by using the signal generated in the real time simulator. Hence, the desired current can be excited and this control achieves fast response. In addition, the current PI controller part will work to compensate disturbances which are not considered in the real time simulator such as the error of the modeling due to temperature variation.

The voltage command is calculated based on feed forward voltage command, compensation voltage command and feed 

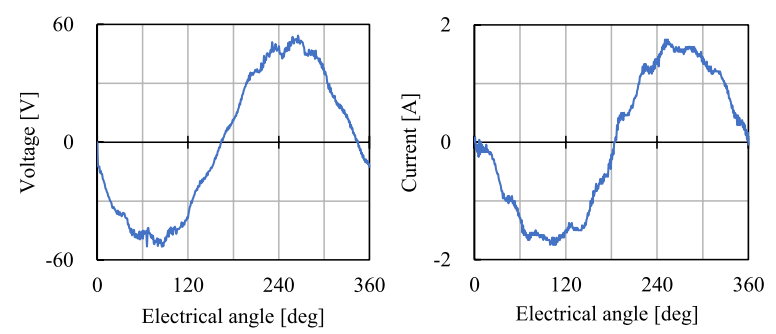

(a) Convention method (Current feedback control)
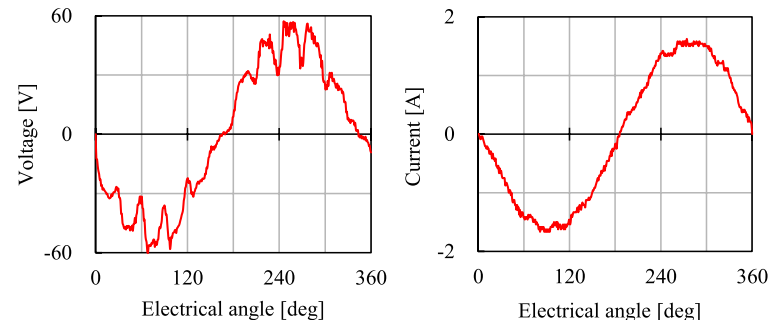

(b) Proposed method (Current feed forward control with current feedback control)
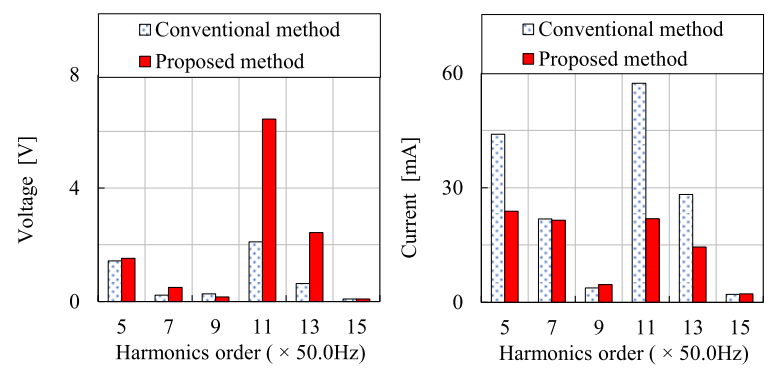

(c) FFT results

Fig. 9. Experimental results of current control in steady state (U-phase voltage waveform is shown in left side and U-phase current waveform is shown in right side)

back voltage command are expressed as follow:

$$
\left[\begin{array}{l}
v_{d[k+1]}^{*} \\
v_{q[k+1]}^{*}
\end{array}\right]=\left[\begin{array}{l}
v_{d F F[k+1]}^{*} \\
v_{q F F[k+1]}^{*}
\end{array}\right]+\left[\begin{array}{l}
v_{d \_c o m p[k+1]}^{*} \\
v_{q_{\_} c o m p[k+1]}^{*}
\end{array}\right]+\left[\begin{array}{l}
v_{d F B[k+1]}^{*} \\
v_{q F B[k+1]}^{*}
\end{array}\right]
$$

where, $v^{*}{ }_{d F B}$ and $v^{*}{ }_{q F B}$ are d-axis feed back voltage command and $q$-axis feed back voltage command, respectively.

Figure 9 shows the experimental results of the conventional current control and the proposed current control in the steady state. The condition of this verification is shown in Table 3 and the motor model $\mathrm{B}$ is used for the experimental test. As shown in Figs. 9(a), (b) and (c), in the conventional current control, U-phase current is distorted by spatial harmonics. In the proposed current control, the harmonics in U-phase current are reduced in comparison with conventional one. Also in the proposed current control, the voltage command is pulsating because the voltage commands are generated to achieve the desired current.

Figure 10 shows the experimental results of the conventional current control and proposed current control in the transient state. The condition of this verification is shown in Table 3. As shown in Fig. 10(a), the proposed current control can achieve the fast response in comparison with the conventional one. In Fig. 10(b), the proposed current control utilizes the maximum level of the limited voltage until the current agrees with the command to achieve the fast response because the voltage limit compensation part gives maximum
Table 3. Experimental condition of current control

\begin{tabular}{|c|c|c|}
\hline & Steady state & Transient state \\
\hline$d$-axis current command [A] & 0 & 0 \\
\hline$q$-axis current command[A] & 2.0 & $0.5 \rightarrow 2.0$ \\
\hline Rotation speed [rpm] & 1500 & 300 \\
\hline DC link voltage [V] & \multicolumn{2}{|c|}{200} \\
\hline Carrier frequency $[\mathrm{kHz}]$ & \multicolumn{2}{|c|}{50} \\
\hline Simulator sampling time $[\mu \mathrm{sec}]$ & \multicolumn{2}{|c|}{} \\
\hline
\end{tabular}

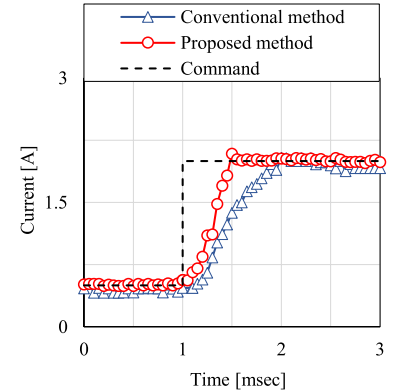

(a) $q$-axis current response

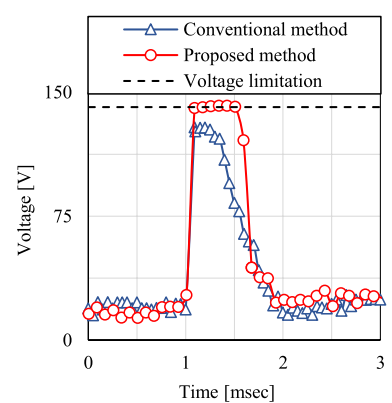

(b) $d q$-axis voltage
Fig. 10. Experimental results of current control in transient state

voltage command to correspond with the command on next sampling step.

From these results, the proposed current control which uses the real time simulator installed the inverse behavior motor model can achieve good tracking performance in the steady state, and can achieve fast response in the transient state.

\section{Conclusion}

This paper presented the advanced torque ripple control and current control based on precise motor model called as "behavior motor model". The circuit simulator installed the behavior model is applied in the real time simulator to develop the advanced PMSM drive system. This system can realize these advanced controls taking the nonlinear characteristics of tested motor into account. The proposed torque ripple control based on the instantaneous torque estimation by the behavior motor model can give the optimal current command to achieve smooth torque because the behavior motor model can estimate the instantaneous torque including the torque ripples according to spatial harmonics. The proposed current control based on the inverse behavior motor model can achieve the desired current because the inverse model uses precise motor parameters to generate the optimal voltage commands. In addition, this control achieved fast current response with consideration of the voltage limitation. Based on the experimental verification, the proposed advanced torque ripple control and current control implemented by the real time simulator proved higher performance than the conventional ones.

\section{References}

( 1 ) B. Stumberger, B. Kreca, and B. Hribernik: "Determination of parameters of synchronous motor with permanent magnets from measurement of load conditions", IEEE Trans. Energy Convers., Vol.14, No.4, pp.1413-1416 (1999)

( 2 ) B. Stumberger, G. Stumberger, D. Dolinar, A. Hamler, and M. Trlep: "Evaluation of saturation and cross-magnetization effects in interior 
permanent-magnet synchronous motor", IEEE Trans. Ind. Appl., Vol.39, No.5, pp.1264-1271 (2003)

( 3 ) S. Clenet, Y. Lefèvre, N. Sadowski, S. Astier, and M. Lajoie: "Compensation of permanent magnet motors torque ripple by means of current supply wave shapes control determined by finite element method", IEEE Trans. Magn., Vol.29, No.2, pp.2019-2023 (2003)

( 4 ) N. Nakao and K. Akatsu: "Torque ripple control for synchronous motors using instantaneous torque estimation”, IEEE Energy Conversion Congress and Exposition, Phoenix, AZ, pp.2452-2459 (2011)

( 5 ) B. Guan, Y. Zhao, and Y. Ruan: "Torque Ripple Minimization in Interior PM Machines Using FEM and Multiple Reference Frames", IEEE Conference on the 1st Industrial Electronics and Applications 2006 (ICIEA 2006), Singapore, pp.1-6 (2006)

( 6 ) P. Blaha and P. VacIavek: "Adaptive control of pm synchronous motor using dead-beat current controllers", in Electrical Machines and Systems, 2009. ICEMS 2009. International Conference on, pp.1-5 (2009)

( 7 ) D.G Holmes and D.A. Martin: "Implementation of a direct digital predictive current controller for single and three phase voltage source inverters", IEEE IAS Annual Meeting, pp.906-913 (1996)

( 8 ) L. Springob and J. Holtz: "High-bandwidth current control for torque ripple compensation in PM synchronous machines", IEEE Trans. Ind. Electron., Vol.45, No.5, pp.713-721 (1998)

( 9 ) Y. Kano, K. Watanabe, T. Kosaka, and N. Matsui: "A Novel Approach for Circuit-Field-Coupled Time-Stepping Electromagnetic Analysis of Saturated Interior PM Motors", IEEE Trans. Ind. Appl., Vol.45, No.4, pp.1325-1333 (2009)

(10) K. Narita, Y. Sakashita, T. Yamada, and K. Akatsu: "Iron Loss Calculation of PM Motor by Coupling Analysis between Magnetic Field Simulator and Control Simulator", Proc. of 11th Int. Conf, on Electrical Machines and Systems (ICEMS 2008), Wuhan (China) (2008)

(11) M. Usui, N. Nakao, and K. akatsu: "Motor control methods with behavior model based on FEA results", Proc. of 2013 IEEE 10th International Conference on Power Electronics and drive System (PEDS), pp.445-450 (2013)
Ryo Tanabe (Student Member) was born Ishikawa, Japan in 1991.

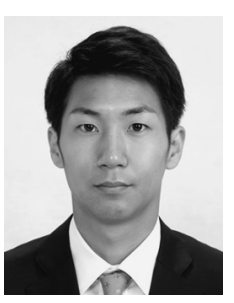
He received the B.S. degrees in electrical engineering from Shibaura Institute of technology, Tokyo, Japan, in 2014. His research interests include the advanced control system and method of Permanent magnet synchronous motors.

Kan Akatsu (Member) received the B.S., M.S., and Ph.D. degrees

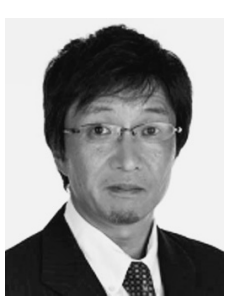
from Yokohama National University, Japan, in 1995, 1997, and 2000, respectively, all in electrical engineering. In 2000, he joined the Nissan Research Center, Yokosuka, Japan, where he contributed to the design and analysis of the new concept permanentmagnet machines. In 2003, he joined the Department of Electrical and electric Engineering, Tokyo University of Agriculture and technology, Tokyo, Japan, as an Assistant Professor. From 2005 to 2007, he was the recipient of a Japan Society for the Promotion of Science Postdoctoral Fellowship for Research Abroad and was a Visiting Professor with the Wisconsin, Electric Machines and Power Electrics Consortium, University of Wisconsin, Madison. Since 2009, he was an Associate Professor and from 2015 he is a professor with Shibaura Institute of Technology, Tokyo. His research interests are motor control, motor design, and power electronics. Dr. Akatsu is a member of the IEEE Power electronics, IEEE Industry Applications, and IEEE Industrial Electronics Societies, and the Institute of Electrical engineers of Japan. 